Bond University

Research Repository

\title{
Implementing Team-Based Learning (TBL) in Accounting Courses
}

Christensen, Jacqueline; Harrison, Jennifer; Hollindale, Janice; Wood, Kayleen

Published in:

Accounting Education

DOI:

10.1080/09639284.2018.1535986

Licence:

Unspecified

Link to output in Bond University research repository.

Recommended citation(APA):

Christensen, J., Harrison, J., Hollindale, J., \& Wood, K. (2019). Implementing Team-Based Learning (TBL) in Accounting Courses. Accounting Education, 28(2), 195-219. https://doi.org/10.1080/09639284.2018.1535986

\footnotetext{
General rights

Copyright and moral rights for the publications made accessible in the public portal are retained by the authors and/or other copyright owners and it is a condition of accessing publications that users recognise and abide by the legal requirements associated with these rights.
}

For more information, or if you believe that this document breaches copyright, please contact the Bond University research repository coordinator. 


\section{Implementing Team-Based Learning (TBL) in Accounting Courses}

JACQUELINE CHRISTENSEN $\dagger$, JENNIFER L. HARRISON $\dagger$, JANICE HOLLINDALE*, KAYLEEN WOOD†

* Bond University, Gold Coast, Australia

† Southern Cross University, Gold Coast, Australia

Correspondence Address: Assistant Professor Jan Hollindale, Bond Business School, Bond University, University Drive, Robina, Gold Coast, Australia, 4229. Tel: (+61) 75595 2248. Email: jhollind@bond.edu.au 


\section{Implementing Team-Based Learning (TBL) in Accounting Courses}

\section{ABSTRACT}

Accounting education has been criticised for ill-equipping graduates for professional employment, with calls for accounting students to acquire a broader range of skills. Working in teams is an important employability skill, yet students generally have negative perceptions of group work. This paper describes a different approach to group work, team-based learning (TBL). Students of introductory accounting courses were organised into permanent strategic teams and worked on multiple team activities. We examined their perceptions of TBL as a key pedagogical component of their learning activities. Compared to a control sample, our findings suggest that the TBL experience improved some attitudes, particularly among quantitatively inclined students. After experiencing TBL, students believed their teamwork abilities had improved, particularly those related to cultural diversity. Students generally believed that their ability in performing the roles of task leader, socio-emotional leader, and information provider improved significantly, as did their preferences for performing the two leadership roles.

KEY WORDS: team-based learning, work-ready graduates, diversity, online peer evaluation software, CATME 


\section{Implementing Team-Based Learning (TBL) in Accounting Courses}

\section{Introduction}

The principal research question addressed by this study is whether the pedagogical approach of team-based learning (TBL) improves university introductory accounting students' attitudes and perceptions relating to teamwork. Teamwork is a professional skill which enables an accountant to work and interact effectively with others, and is an important component of international accounting education standards relating to professional competence (IFAC International Accounting Education Standards Board, 2017). The development of teamwork skills is often overlooked in university curricula, or, if present, is given token coverage.

Accounting educators can develop their students' skills in this important competence area by designing a pedagogical environment in which skills in cooperation, communication, cultural awareness, listening, interviewing, negotiation, conflict resolution and problem solving play a factor. Thus, TBL as a pedagogical approach, and this research documenting the results of the implementation of TBL, is of interest to accounting educators around the globe because of its applicability in better preparing their students for their professional careers. Furthermore, as this paper provides an overview of our TBL implementation process, it is of relevance to accounting other academics seeking to develop teamwork skills in their students through the adoption of a different approach to student learning.

Our principal research question was addressed by using pre- post-test methodology, through which we surveyed students. This allowed us to evaluate changes in students' beliefs and abilities towards TBL, and changes in their perceptions of their abilities and preferences towards various team roles. Secondary research questions were similarly explored.

Accounting, typically a core requirement for students pursuing business degrees (Warren \& Young, 2012), is said to be the language of business, and an understanding of financial and managerial accounting concepts is a pre-requisite for anyone contemplating a career in business. However, anecdotal evidence and evidence from a large body of research in the accounting education literature suggest a significant proportion of students have a negative perception of introductory financial accounting subjects (Warren \& Young, 2012). Student perceptions are important. Selecting a major and choosing a career are influenced by perceptions derived from tertiary education experiences (Jackling, 2002). 
Nelson (1995) found a strong relationship between attitude towards accounting and its selection as a major, hence affecting students’ decisions about career goals. Similarly, Cohen and Hanno (1993) concluded that non-accounting majors believed that accounting has an image of being boring and too quantitative, which is unattractive to bright non-accounting majors. They further conclude that increased emphasis on people skills and communication skills in introductory courses might increase the appeal of accounting as a major and as a career to quality students.

Indeed, accounting education has been criticised for over-emphasising technical abilities of graduates and neglecting organisational, interpersonal, and communicative skills, important for entry into the profession (Adler \& Milne, 1997). Various researchers have voiced viewpoints that accounting students are ill-equipped to begin professional practice because they are not proficient in generic skills sought by employers (Kavanagh \& Drennan, 2008).

The ability to work in teams is one of several generic skills identified as important employability skills (Opdecam \& Everaert, 2012; Shaw, 2004; Woodley \& Armatas, 2010). Yet, as Paguio and Jackling (2016) argue, employers express concern that teamwork skills are lacking in many university graduates. Furthermore, many graduates are not confident in their ability to work in teams when they begin employment (Woodley \& Armatas, 2010) and are critical that more attention was not paid to developing teamwork skills throughout their degree (Crebert, Bates, Bell, Patrick, \& Cragnolini, 2004). An increased emphasis on team building skills in accounting education is largely being driven by the accounting profession, according to Bryant and Albring (2006), who identify various leading professional accounting bodies that accentuate the importance of these skills.

This paper describes the implementation of TBL in undergraduate and postgraduate accounting units in an Australian university. TBL pedagogy comprises a set of instructional activities which disrupts the distinct traditional roles of instructor and students of postsecondary education, and puts the emphasis on learning, not on teaching, and is founded in social constructivist theory (Michaelsen \& Sweet, 2008). Our study is concerned with students' attitudes and perceptions towards accounting, teamwork, and team role-preferences, and how those attitudes might be affected after experiencing the non-traditional pedagogical approach taken by TBL. Knowledge of these attitudes could inform the pedagogy of 
accounting subjects to better enhance student engagement and learning, and develop the nontechnical skills required of accounting graduates as they enter the profession.

Research on TBL has tended to investigate how TBL affects students’ content knowledge outcomes (see Swanson, McCulley, Osman, Scammacca Lewis, \& Solis (2017) who provide a meta-analysis on relevant intervention studies). This paper contributes to the literature as it provides students' perceptions on TBL as a learning tool, as well as their perceptions on their ability to work in a diverse team-setting, and their perceived abilities and preferences for various roles within the team. Furthermore, this paper specifically focuses on the discipline of accounting, a profession in which critical interpersonal skills sought by employers are considered lacking by both employers and graduates.

Our results indicate that, compared to a control sample, the TBL experience improved some attitudes towards accounting, particularly among quantitatively inclined students. After experiencing TBL, students believed their teamwork abilities had improved, particularly those related to cultural diversity. Students generally believed that their ability in performing the roles of task leader, socio-emotional leader, and information provider improved significantly, as did their preferences for performing the two leadership roles.

\section{Contribution}

Professional competence of accountants relies on more than the possession of knowledge of accounting principles, standards, concepts, facts, and procedures (IFAC International Accounting Education Standards Board, 2017). Rather, professional competence also requires an amalgamation and application of professional skills, and professional values, ethics and attitudes (IFAC International Accounting Education Standards Board, 2017). The ability to work in teams is an essential component of professional skills. Thus, providing university students with practical and sustained teamwork experience during their accounting studies is directly relevant to their development of professional competence. This study on implementing TBL contributes to accounting education because of its potential to inform and improve teaching and learning practices to include those that are designed to develop important employability skills in university accounting students.

Pertinent literature is reviewed in the next section. An account of how we implemented TBL follows. The next sections present our research questions, research method, results and discussion. In the final section, the paper concludes, and presents our contribution and limitations of this research. 


\section{Literature Review}

Team-based learning (TBL) is usually implemented as a defined instructional method of teaching (Michaelsen \& Sweet, 2008), which includes a particular set of instructional activities (Michaelsen \& Sweet, 2011). Defined instructional activities can include prereading outside of class, individual and team readiness assessment testing, real-time feedback, challenging or appealing of answers marked as incorrect, and application exercises. This pedagogy is not a new concept in higher education, having its origins in the late 1970s (Michaelsen, Bauman Kight, \& Fink, 2002) in college organizational behaviour classes (Michaelsen, Watson, Cragin, \& Fink, 1982). TBL is an approach that is considered applicable to any class context (face-to-face, online) (Gomez, Wu, \& Passerini, 2010) and has often been used to assist students in developing team skills (Betta, 2016). While grouprelated learning environments are frequently used in most disciplines (Anson \& Goodman, 2014), the team learning process differs from traditional group-oriented instruction because of the conditions under which learning takes place. Specifically, in TBL, group composition, the focus of class activities in the instructional process, the sequencing of instructional activities, and approaches for developing group cohesiveness are all intentionally designed for students to take responsibility for their learning and their peers' learning (Michaelsen et al., 1982).

\section{Team-based learning versus group learning}

There is general acceptance that students should engage in group work activities. Most universities include collaboration and leadership as a graduate attribute and many specifically refer to teamwork as a desirable outcome. The CPA Horizons 2025 Report (American Institute of Certified Professional Accountants (AICPA), 2011) has identified the core competencies of leadership, integration, and collaboration as part of the essential beliefs, service focus, skills, and knowledge required for CPAs to remain competitive into the 21st century. In university accounting courses, group activities commonly consist of a one-off group assignment involving data collection, research, and writing up a report. The majority of the assignment is conducted outside of the classroom, typically over a period of 3 to 4 weeks. In general, these traditional groups are not popular and common complaints include coordinating meeting times (Woodley \& Armatas, 2010), accounting for the range of individual contribution, in particular underperforming members, described as hitchhikers versus workhorses (Clinton \& Kohlmeyer III, 2005; Cottell Jr \& Millis, 1992), and awarding 
grades for overall outcome (Woodley \& Armatas, 2010). However, group work is perceived by students of the disciplines of business, accounting and economics to be a 'worthy learning strategy’ (Handal, Wood, \& Muchatuta, 2011, p. 13).

Replacing the group work paradigm with one of team learning not only overcomes many of the negative aspects of group work but provides considerable benefits (Michaelsen et al., 2002). TBL is characterised by a longer lifecycle and integrated assessment and instruction, with a pluralistic approach using authentic activities (Dochy, Segers, \& Sluijsmans, 1999). There is continuous dialogue between the team members, and with the teacher, encouraging reflection and collaboration, and incorporating self, peer, and teacher formative assessment (Dochy et al., 1999).

\section{Social constructivism theory}

The pedagogy of TBL is grounded in the theoretical framework of social constructivism. Developed in cognitive psychology by Vygotsky in the late 1970s, social constructivism was an alternative to Piaget's cognitive constructivism, which separated learning from context. Constructivism is a theory of learning, rather than a description of teaching (Fosnot \& Perry, 1996). Constructivism focuses on shifting the traditional teacher-to-learner knowledge transfer paradigm with that of the learner being an active agent in the learning process (Han \& Newell, 2014).

With an emphasis on learning via collaboration, Vygotsky placed more emphasis on the social context of learning. TBL by definition and design engages learners in a social learning space. Social constructivism addresses student motivation in terms of behaviour (extrinsic) and cognition (intrinsic), and posits that social behaviour reward and active internal construction of knowledge, combine to engage students in transformational learning (Bowen, 2005). Learning, in turn, becomes enculturated into a community of practice. In social constructivism, social communication in any of its forms is recognised as essential in a collaborative process of learning.

\section{Implications for team-based learning in accounting courses}

TBL requires students to develop social communication skills in order to convey and combine their individual learning for the success of the team. In TBL a constructivist teacher creates the context for learning which engages students in stimulating activities that encourage and facilitate learning, and thus promote active learning. Other concepts, including 
scaffolding, are also used as means of supporting and contributing to learning. Scaffolding helps students to become active learners, which should help accounting students to apply accounting concepts to solve real-life problems in a range of contexts, and develop a real mastery of accounting (Helliar, 2013).

Scaffolding enables a learner to 'solve a problem, carry out a task or achieve a goal which would be beyond his unassisted efforts' (Wood, Bruner, \& Ross, 1976, p. 90). Providing assistance in the students' learning process, in the form of hard and soft scaffolding, it increases understanding (Chen \& Law, 2016). Hard scaffolds are fixed information and question prompts. Soft scaffolds are spontaneous and timely feedback and supports which guide team interaction and collaboration. Scaffolding is removed once the student masters the task. Using hard and soft scaffolds (Biggs, 1987; Kapp \& O'Driscoll, 2009), the teacher assists students as they approach problems, interjects with troublesome concepts to disrupt existing beliefs and advance critical thinking, and provides formative feedback. Students make sense from hard scaffolds and elicit connections between the TBL scenario and real world situations when concepts and question prompts are well-structured (Chen \& Law, 2016). Used together, hard and soft scaffolds create 'collaborative opportunities to provide and receive feedback, co-construct ideas, resolve dilemmas, negotiate meaning and make team decisions' (Chen \& Law, 2016, p. 1203). The use of hypothetical scenarios grounded in real world situations are interesting, relatable, and can produce satisfying learning outcomes for students (Chen \& Law, 2016).

Thus the primary learning objective of TBL pedagogy is to go beyond just covering content, and focus on providing an environment where students have the opportunity to practice course concepts and problem-solve (Michaelsen et al., 2002; Michaelsen \& Sweet, 2008), and learn generic, or transferable skills, that equip students for a professional career. This is especially relevant for students aspiring towards a career in the accounting profession, which requires not only the understanding and application of highly technical core concepts which are fundamental for decision-making purposes, but also the possession of important interpersonal skills and professional skills.

International students with English as a second language or a non-English speakingbackground, report that working in a TBL environment improves their English comprehension, speaking, and writing skills (Woodley \& Armatas, 2010). Given that TBL relies on peer-assisted learning, where students are teaching other students, promoting deeper 
understanding and confidence, it enhances interpersonal and communication skills (Candy, 2000). Also the familiarity generated by working in teams helps students to understand that debate is an essential part of learning and not personal attack (Adler \& Milne, 1997). As a significant proportion of the course content is delivered through team activities and assignments, students involved in TBL work together to accomplish shared goals, seeking outcomes that are beneficial to everyone (Johnson \& Johnson, 1999).

\section{Team-based learning strategy}

With TBL, students are organised into permanent strategic teams to create a cooperative learning environment for the duration of the semester. They work on multiple group activities to improve learning via development of self-managed learning teams (Johnson \& Johnson, 1999; Michaelsen et al., 2002; Opdecam \& Everaert, 2012). Cooperative learning is based on the concept of small groups working together to achieve a common goal, mastery of a concept, solve a problem, or accomplish an academic task such as a report or assignment.

There is an extensive body of research providing evidence that cooperative learning results in higher achievements and has a positive effect on students. The majority of comments from studies are positive (Lightner, Bober, \& Willi, 2007), reporting students are more motivated, satisfied, and their problem solving skills have improved. They are happier, have higher self-esteem, are much more engaged and very pleased to be learning networking, team building, and leadership skills (Caldwell, Weishar, William, \& Glezen, 1996; Clinton \& Kohlmeyer III, 2005; Cooper \& Mueck, 1990; Lightner et al., 2007; Opdecam \& Everaert, 2012; Woodley \& Armatas, 2010).

Interdependence among members is a characteristic of small groups and teams, as are communication skills that enhance the chances of working effectively and efficiently towards the achievement of common tasks (Cragan, Wright, \& Kasch, 2008). TBL intentionally does not recommend the assignment of team roles (Michaelsen \& Sweet, 2011). Roles typically emerge from the transactions conducted among members in new (i.e., zero-history as a group), small, informal, leaderless groups (Rothwell, 2013). Informal roles emphasise functions, rather than positions and actual duties and specific behaviours expected from a group member, and more than one person can perform each informal role (Myers \& Anderson, 2008). According to Michaelsen et al. (2002), giving teams responsibility for deciding the roles and functions of its members, as opposed to instructors handing out assigned roles, is important. Students learn on their own about getting things done effectively 
and efficiently. Furthermore, it is the teams who monitor individual and group performance, and who work on ways to improve their performance.

Following is an overview of the authors' implementation of TBL into accounting subjects.

\section{Implementation of team-based learning}

The course outline advises enrolling students that TBL will be an essential element of the course and provides a brief overview, e.g. rationale, team formation process, team assessment activities, and impact on grade. Students are advised that teams will be formed at the start of the semester. The aim is to get active student involvement from the beginning to promote peer-assisted learning (Adler \& Milne, 1997). The first lecture explains to students why TBL is used and provides them with an overview of its features and benefits, including how TBL impacts delivery of the subject, e.g. how teams will be formed, agreeing on a team code of conduct to set expectations up front, and the necessary roles within each team. Information is given to alleviate concerns about grading, and setting up mechanisms to encourage development of positive group norms (Johnson \& Johnson, 1999). Teams are generally formed in week 2 to allow for late comers to the course, and teams generally commence working together in class from week 3 until week 12. Thus, over the duration of the course, and allowing for a mid-semester review class, where no team activities were conducted, teams met and worked together in class around 18 to 19 times. Teams would also meet outside of class (data not recorded) to complete a team assignment.

\section{Team formation and management}

Students do not self-select into teams; rather the instructor decides on a number of parameters for team formation e.g., team size and diversity, and allocates students to teams. Typically, teams consist of 5 to 7 members. This size affords teams the intellectual resources necessary to achieve the learning objectives and assessment items, and maximises diversity, based on the Michaelsen et al. (2002) guidelines. Diverse groups have the benefits of a larger variety of resources, ideas and perspectives, leading to greater creative potential (Cottell Jr \& Millis, 1992; Shaw, 2004). Following Michaelsen et al. (1982), to maximise team diversity, information was obtained from the class by asking students about their background: gender, age, country of origin, degree enrolled in, and work experience (Han \& Newell, 2014). Based on their responses, and starting with the least common category, students stood and were counted off into teams. As classes at this university are generally quite small, this process 
was not overly time-consuming and was often accompanied by much good humour. Admittedly, in the case of larger classes, selecting of team members through this process might be less efficient.

Because these teams will work together throughout the whole of the course they have time to determine the roles of the members and organise themselves into a working unit, without assignation from the teacher. Furthermore, roles played by each member are likely to occur organically, and may vary during the completion of team tasks. Pursuant to role emergence theory (Cragan et al., 2008), the task leader naturally emerges in small task groups. The team then typically progresses through stages of primary tension, where the tension releaser role is identified, i.e., the person who opens the communication. Secondary tension tends to follow, where team members compete for positions based on perceived status and their intrinsic strengths, filling the remaining roles of social emotion leader, central negative (or devil’s advocate), and information provider (Cragan et al., 2008). While information about each of these roles was presented at the introductory lecture at the start of the semester when an overview of TBL was provided, it should be revisited when teams are formed. It is important for the instructor to point out to each team that team roles may change from task to task, to provide a different lens and avoid 'group think', where decisions go unchallenged and which could result in unsatisfactory outcomes. In the role formation process team members begin to develop effective and appropriate communication skills, to work cooperatively and achieve the assigned tasks.

These authors used CATME ${ }^{1}$, an online teamwork management system developed by academics in the US, which at the time was available free for teachers anywhere. Teams were set up in CATME, which then prompted students to register and set up a password within their system, and then to conduct peer evaluation at two points during the semester.

\section{Flipped classroom approach}

A key element of any TBL initiative is the requirement for students to do some pre-class preparation such as reading, reviewing PowerPoints, or researching. This pre-learning

${ }^{1}$ CATME SMARTER Teamwork is a system of secure, web-based tools that enable instructors to implement best practices in managing student teams. The tools and training are supported by the literature on teamwork and training, along with independent empirical research. A licence fee, payable in arrears, was instituted from 1st July 2017 (http://info.catme.org/about/). 
activity, a key feature of the flipped classroom approach, allows the teacher to replace the traditional lecture with discussion of the material, answering questions, addressing issues, and applying the principles through doing activities. The flipped classroom model of delivery, which we adopted, is described by Lage, Platt, and Treglia (2000, p. 32), as inverting the classroom, 'mean[ing] that events that have traditionally taken place inside the classroom now take place outside the classroom and vice versa'. There is much evidence that flipping the classroom enhances the student learning experience (Butt, 2014). Focus on delivering the content in class at a higher level and facilitating team activities shifts the teacher's role from one of primarily dispensing information to facilitating student learning. The students' role becomes more proactive as they accept responsibility for their learning by being prepared for in-class activities (Michaelsen \& Sweet, 2008).

\section{Readiness Assessment Tests (RATs)}

Given that pre-class preparation is required, at the start of a new topic and before any classroom instruction on it begins, students take a short in-class quiz (typically 4, but no more than 10 multiple choice questions) to test key concepts from the assigned readings. These quizzes are generally referred to as Readiness Assessment Tests or RATs ${ }^{2}$ (Michaelsen \& Sweet, 2008), an acronym that students tend to find amusing. RATs were administered in class on five occasions, typically on a fortnightly basis as we were concerned with 'overassessing', but also this frequency is in line with Michaelsen and Sweet's (2008) recommendation of five to seven RATs in each term. Course outlines stipulated the weeks in which a RAT would be given.

${ }^{2}$ RATs may be administered in either paper-based or digital formats. Mobile technology (e.g., Socrative, Kahoot, Pingo, and Poll Everywhere) can be used to automatically mark the answers submitted online, alleviating the need for manually marking the quizzes and reducing the instructor's workload. In a digital format, the textbook’s test bank multiple choice questions are uploaded to an online learning platform and released at the time of the RAT. Images can be uploaded to accompany the questions to make the quiz more engaging. The online platform also facilities distance education. For example, if a student is off campus, they are able to go online at an assigned time and complete the quiz to satisfy the individual assessment component. These authors have more recently used Socrative for the development and delivery of the RAT quizzes. 
A RAT is first taken and submitted on an individual basis, and upon its completion, the same RAT is then taken again as a team. This requires all team members to come to a consensus on the answers, so lack of preparation will hinder the team effort (Clinton \& Kohlmeyer III, 2005; Michaelsen \& Sweet, 2008). At the completion of the RATs the instructor provides feedback by going through the solutions and therefore having the opportunity to clarify any misconceptions. In the immediate aftermath of this test, students are more motivated to ask questions and the learning environment is much more dynamic. For example, some of the RAT questions can be deliberately ambiguous, providing the opportunity for students to argue their understanding and thus demonstrate higher level thinking skills. Students receive an individual mark and a team mark for correct answers (students could earn a maximum of $5 \%$ of their overall grades for the course for their individual RATs, and a further 5\% for their team RATs), which contributes to their overall grade for the course. The team RAT mark also contributes towards a 'best performing team' award at the end of the semester. This award is used to foster a competitive spirit amongst the teams. The prize is on two criteria, the highest team RAT score and the best team presentation as judged by peers via a vote/poll and the instructors. Interestingly it was embraced more enthusiastically by the postgraduate students than the undergraduate students.

The TBL process is depicted diagrammatically in Figure 1.

[Insert figure 1 here] 


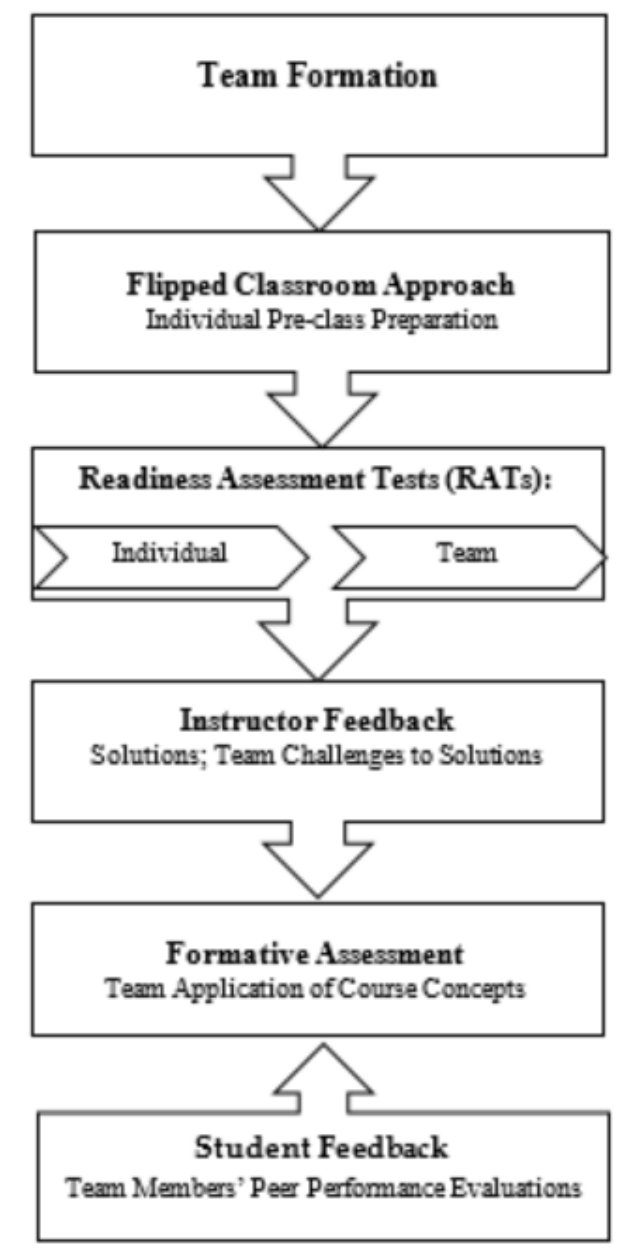

Figure 1: TBL Process

\section{Formative assessment}

TBL was incorporated into the traditional lecture/tutorial timetabling where typically there are two sessions each week. The first session covers key elements of the set readings (after administration of the individual and team RATs) interspersed with team activities where students are presented with problems that require them to apply the content (Michaelsen et al., 2002; Michaelsen \& Sweet, 2008). This promotes discussion both within and between groups. The second session, the tutorial or review seminar, focuses more on application of the principles covered, and this also provides opportunities for teamwork and for formative assessment in a less-intimidating environment. For example, in team activities, team members can pool their individual efforts, present a team model answer to a case and lead discussion. Teams are guided to avoid lecturing or giving canned solutions, and may be encouraged to design learning activities to explore the issue in depth, challenge initial 
conceptions of the topic, and even encourage controversy if appropriate (Adler \& Milne, 1997).

\section{Team members' performance feedback}

Timely feedback on individual team member's performance in team assessment activities and team dynamics is essential. Students are required to register with the CATME online peer evaluation tool and undertake two peer-review processes to assess the contributions of each team member. The first is mid-way through the course to act as an early warning device and to provide team members with peer feedback on their contribution, giving students the opportunity to improve their performance within the team, and to allow mentoring and advice from the instructor if required. The second peer evaluation takes place at the end of the semester, when the peer ratings impact the student's mark for designated team assessment activities. This staged formative assessment and the perceived objectivity afforded by an independent third-party provider (CATME) mitigates the ongoing requirement for instructor intervention to investigate dissatisfaction with team assessment grades awarded to the individual team members.

\section{Research Questions}

Given that anecdotal and research evidence (e.g., Helliar, 2013) indicates that students have negative perceptions of accounting, we were interested in whether TBL would positively improve students' perceptions and attitudes to this field of study, and whether students viewed TBL as a tool for learning. Furthermore, as team-based teaching and learning activities offer an interactive and very social way of achieving a comprehensive approach to acquiring employability skills relevant to the accounting profession (Lightner et al., 2007), we also sought to determine what students thought about their abilities to work effectively in diverse teams, and how they perceived their abilities and preferences for the various roles that develop through the completion of team tasks might have changed during the semester.

This study therefore addresses the following research questions:

1. Does the implementation of TBL in introductory accounting courses enhance student perceptions and attitudes towards accounting?

2. Does the implementation of TBL enhance students' perceptions of the teamwork experience as a learning tool in a university accounting course? 
3. Does the implementation of TBL in accounting courses enhance students' perceptions of their abilities to work effectively in diverse teams?

4. Does the implementation of TBL in accounting subjects enhance students' perceptions of their ability and preference for five identified roles that commonly emerge in teams?

\section{Research Method}

\section{Design and data collection}

Prior studies that have used a pre - post-test design to capture student perceptions of cooperative learning in business courses include Caldwell et al. (1996), Opdecam and Everaert (2012), Shaw (2004), and Shaw, Fisher and Southey (1999). Students' perceptions of cooperative learning environments provide useful information in understanding the impact of TBL (van der Lann Smith \& Spindle, 2007). For this study a pre - post treatment survey (see Appendix) was developed as an instrument to examine course specific attitudes to introductory accounting subjects, student attitudes and perceptions to TBL in accounting subjects, and explore students' perceptions of their ability and performance preferences for the roles played in a team setting.

Ethics approval was obtained to survey students in a number of undergraduate and postgraduate accounting classes. An explanatory letter described the purpose of the research and assured students of the confidentiality of their responses. Confidentiality was achieved by the students using a 6-digit private identifier made up of the digits of the student's month of birth, followed by the first two letters of their mother's Christian name, and the first two letters of their father's Christian name. The private identifier was then used to match the students' individual pre - and post - TBL treatment responses. Pre- and post-surveys were identical and administered during class time, however to avoid the potential of a power/dependency relationship the teacher did not intervene in the data gathering process. The first survey was administered at the beginning of week 2 just prior to establishing the teams and then again at the end of week 12 when all substantial team activities were completed. This study was a quasi-experimental design (no random assignment of students) which included all students taking any one of three accounting subjects in 2013 (undergraduates: introductory financial accounting, and management accounting; postgraduates: introductory financial accounting). Reinig, Horowitz and Whittenburg (2011) 
examine student attitudes towards TBL for a single measure, team exams, or RAPs (readiness assurance process) which we refer to as RATs (readiness assessment tests). They note the difficulty of controlling for a novelty effect, which is likely to reduce over time, in a one-shot experimental design. This suggests the creation of permanent strategic teams engaging in multiple team-based activities over an extended experimental period of 10 weeks reduces the likelihood that the treatment effects in our study are based on novelty effects alone.

One introductory accounting class did not participate in the TBL treatment but students did complete questions on demographics and attitudes towards accounting in the surveys. This provided an opportunity to include a control sample for the analysis of course specific attitudes to accounting.

\section{Measures}

The survey instrument contained four sections. The first section collected key demographic information on each student, which included gender, age, work experience and nationality (Shaw, 2004). Along with course and level information, these demographics were used as control variables in the analysis, as attitudes and perceptions are likely influenced by a number of factors. There were seven control variables, described in Table 1, including gender (male, female), student origin (domestic, international), work experience (some, none) and level (undergraduate, postgraduate). Maturity was another control variable, defined as mature ( $\geq 23$ years) and young ( $<23$ years). Twenty-three was chosen as a cut-off based on the 75th percentile age in the sample, which aligns well with previous research (Cochran, Campbell, Baker, \& Leeds, 2014; Kahu, Stephens, Leach, \& Zepke, 2015). We also include a control variable for type of degree or major. Given that introductory accounting is a pre-requisite for all business students at the university, students' attitude and perceptions to an accounting course are likely to vary depending on the degree they are enrolled in. It is also intuitive that students enrolled in degrees majoring in quantitative disciplines (e.g., commerce degrees majoring in accounting, finance, and economics) will have a more favourable attitude to accounting courses than those enrolled in the qualitative disciplines (e.g., business degrees with a focus on marketing, human resources, hotel management). A final control variable relevant only to analyses for research questions 2, 3 and 4, was course, being either an introductory financial accounting course or management accounting course.

[Insert Table 1 here] 
Table 1. Descriptive statistics for control variables

\begin{tabular}{|l|l|c|c|l|c|c|}
\hline Control variable & & $\boldsymbol{n}$ & Percent & & \multicolumn{1}{|c|}{ Percent } \\
\hline Gender & Female & 93 & 44 & Male & 117 & 56 \\
\hline Origin & Domestic & 112 & 53 & International & 98 & 47 \\
\hline Maturity & Young & 147 & 70 & Mature (75th percentile or >) & 63 & 30 \\
\hline Level & Undergraduate & 169 & 80 & Postgraduate & 41 & 20 \\
\hline Degree & Quantitative degree/major & 86 & 41 & Qualitative degree/major & 124 & 59 \\
\hline Course & Introductory Financial Accounting & 175 & 83 & Management Accounting & 35 & 17 \\
\hline Work experience & Yes & 161 & 77 & No & 23 \\
\hline
\end{tabular}

The second section of the survey instrument consisted of eight items to measure course specific attitudes. We asked students in the introductory financial accounting courses to rate firstly, their level of knowledge about accounting (on a 6-point Likert scale ranging from none, very little, some, moderate, high, and very high), and then the extent to which they agree (on a 6-point Likert scale ranging from strongly disagree to strongly agree) with seven further statements. The eight items used to measure students' attitudes to their introductory financial accounting course are derived from the instruments used by Caldwell et al. (1996).

The third section of the survey focused on students' perceptions of TBL and their perceived abilities in group decision making, intercultural issues, motivation, and conflict resolution (Shaw, 2004) using a 6-point Likert scale ranging from almost none, very low, low, moderate, high, and very high. The seventeen items used to measure perceptions of and abilities in the TBL environment are derived from the instruments used by Shaw et al. (1999) and Shaw (2004). Five of the seventeen statements explored student perceptions about the TBL learning experience. The remaining twelve statements explored perceptions of students' abilities in a TBL environment. Items covered abilities related to diversity within teams and various team dynamics and processes. Factor analysis of the items in this section suggested four dimensions: TBL learning experience (five items); cultural diversity abilities (three items); soft skills and leadership abilities (four items); and planning and implementation abilities (four items). The latter three dimensions align well with those of Shaw et al. (1999). Respondent scale scores were created using the mean of the items on the scale. Sample means, standard deviations and Cronbach's alpha for each of the four scales are shown in Table 2.

[Insert Table 2 here] 
Table 2. TBL perceptions and abilities scales - pre-test/post-test means, standard deviations and alphas

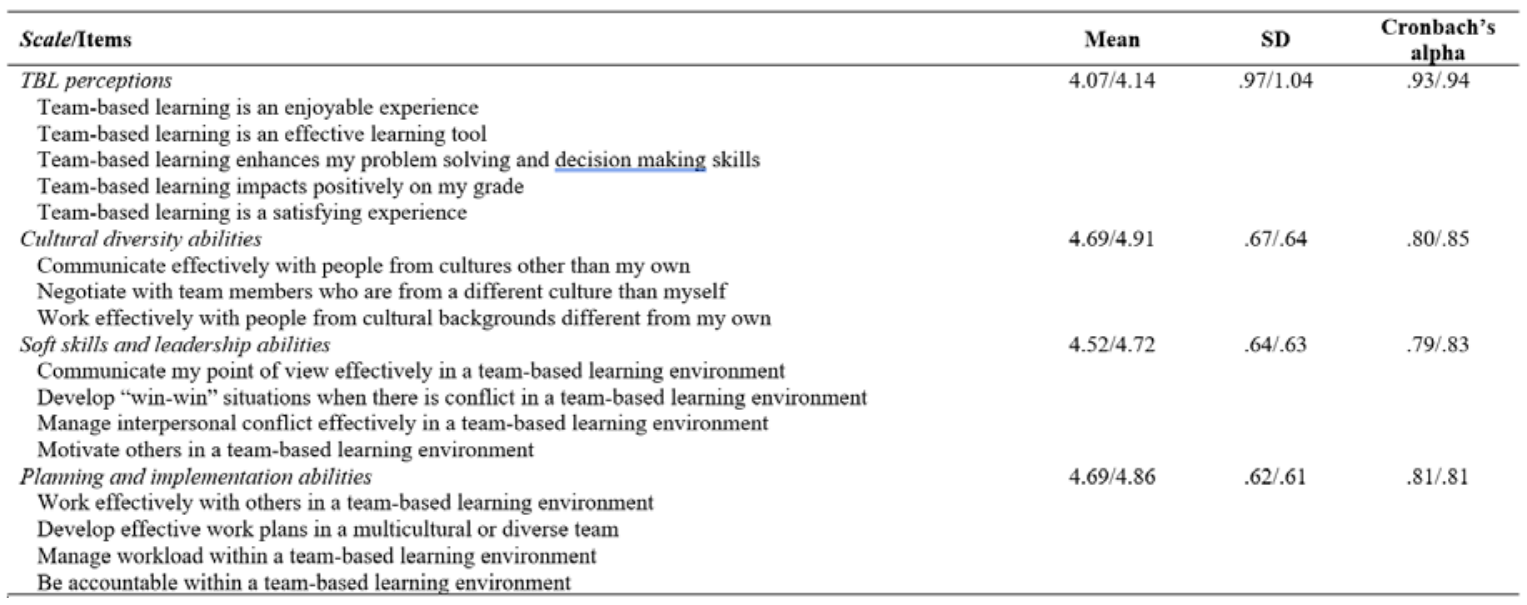

The fourth section in the survey captured students' views of two aspects of performing the five roles as defined by Cragan et al. (2008). A 6-point Likert scale ranging through almost none, very low, low, moderate, high, to very high, was used to capture students' perceptions of both their ability to perform, and their preference for the roles of task leader, socio-emotional leader, devil's advocate, tension releaser, and information provider.

The main method of analysis was paired-samples t-tests to detect differences in preand post-survey responses. Prior to analysis of the data, all items and scales were screened to ensure they met test assumptions.

\section{Results}

Approximately 470 students over three semesters in 2013 were enrolled in the accounting classes and of these 400 filled in the survey (340 undergraduates and 60 postgraduates). Twenty-nine of these students (one class) did not participate in TBL and served as a control sample for analysing course specific attitudes. Although we had an 86 percent response rate, the final sample consisted of 210 matched pairs for the pre- and post- test survey instrument. The reduction was a result of (1) unmatched identifiers between the two surveys and (2) absentees on either the pre- or post-test survey date.

\section{Course specific attitudes}

Recall research question 1 asked whether TBL mitigates negative course specific attitudes in accounting courses. The pre-and post-surveys included eight statements capturing these attitudes in both the TBL treatment and control sample in introductory financial accounting courses. One-way ANOVA was performed first to determine whether there were any significant differences in pre-test survey responses to the eight statements based on relevant 
control variables: gender, origin, age, level, degree, and work experience. No significant differences were found for five of the six control variables. However, as expected, students taking a quantitative degree or major had responses significantly different from those taking a qualitative degree or major. Based on these results, the TBL treatment sample was also split into qualitative and quantitative degree subsamples.

Table 3 below presents the results of paired sample t-tests for differences in the pre post survey responses for course specific attitudes. Results from the control sample were compared with the TBL treatment sample, which was split into qualitative and quantitative subsamples.

\section{[Insert Table 3 here]}

Table 3. Course specific attitudes - paired samples $t$ tests of TBL sample, TBL by degree, and control sample comparing beginning of course with end

\begin{tabular}{|c|c|c|c|c|c|c|c|c|c|c|c|c|}
\hline & \multicolumn{3}{|c|}{ TBL Sample } & \multicolumn{3}{|c|}{ TBL: Qualitative Degree } & \multicolumn{3}{|c|}{ TBL: Quantitative Degree } & \multicolumn{3}{|c|}{ Control Sample } \\
\hline & $\begin{array}{l}\text { Change } \\
\text { in Mean }\end{array}$ & $n$ & Sig & $\begin{array}{l}\text { Change } \\
\text { in Mean }\end{array}$ & $n$ & Sig & $\begin{array}{l}\text { Change } \\
\text { in Mean }\end{array}$ & $n$ & Sig & $\begin{array}{l}\text { Change } \\
\text { in Mean }\end{array}$ & $n$ & Sig \\
\hline $\begin{array}{l}\text { 1. My level of knowledge about } \\
\text { accounting is: none to very high }\end{array}$ & 1.26 & 142 & $0.00^{* * *}$ & 1.37 & 86 & $0.00^{* * * *}$ & 1.11 & 27 & $0.00^{* * *}$ & 1.07 & 29 & $0.00^{* * *}$ \\
\hline 2. Accounting is interesting & -0.03 & 175 & 0.66 & -0.01 & 108 & 0.93 & 0.13 & 38 & 0.39 & -0.34 & 29 & $0.04 * *$ \\
\hline $\begin{array}{l}\text { 3. You must understand } \\
\text { accounting to solve business } \\
\text { problems }\end{array}$ & 0.03 & 174 & 0.67 & 0.00 & 107 & 1.00 & 0.21 & 38 & $0.09 *$ & -0.07 & 29 & 0.74 \\
\hline $\begin{array}{l}\text { 4. I am motivated to do well in this } \\
\text { course }\end{array}$ & -0.34 & 175 & $0.00^{* * *}$ & -0.39 & 108 & $0.00^{* * * *}$ & -0.24 & 38 & $0.03^{* *}$ & -0.28 & 29 & $0.03^{* * *}$ \\
\hline $\begin{array}{l}\text { 5. Accounting information is } \\
\text { essential in business planning }\end{array}$ & -0.10 & 174 & $0.10^{*}$ & -0.19 & 107 & 0.02 ** & 0.00 & 38 & 1.00 & 0.07 & 29 & 0.68 \\
\hline $\begin{array}{l}\text { 6. Learning accounting is a } \\
\text { stressful experience }\end{array}$ & 0.46 & 172 & $0.00^{* * *}$ & 0.45 & 105 & $0.00^{* * * *}$ & 0.42 & 38 & $0.06^{*}$ & 0.55 & 29 & $0.02 * *$ \\
\hline
\end{tabular}

All four samples/subsamples reported a significant difference in their pre- and posttest perception of accounting knowledge for item 1: 'My level of knowledge about accounting is - from none to very high' $(\mathrm{p}<0.01)$ indicating a positive perception of course learning outcomes, regardless of teaching method. The largest increase in the reported mean value (1.37) was for the TBL qualitative students.

In considering the remainder of the items, some support was found to indicate that TBL lowers negative attitudes towards accounting and studying accounting. Although there was no significant difference in students' attitudes to the statement 'Accounting is interesting' (item 2) in the treatment sample, there was a significant $(\mathrm{p}<0.05)$ decline in the measure for this item for the control sample, indicating accounting became less interesting 
after the course for those students who had no TBL. A possible explanation is that the experience of TBL at least maintained the perceived interest value of accounting.

Quantitative TBL students also showed stronger agreement $(\mathrm{p}<0.10)$ with the statement 'You must understand accounting to solve business problems' (item 3) and their plans to take up a career in accounting (item 8) also significantly increased $(\mathrm{p}<0.05)$ which is logical given their major. This latter effect was not found in the control sample. To examine this further, we conducted a paired samples t-test (untabulated) for difference in preand post- responses to item 8 by quantitative students in the control sample $(n=15)$. No significant difference was found. Taken together, these findings suggest the experience of TBL enhanced attitudes towards an accounting career amongst quantitative students.

Contrary to expectations, negative perceptions actually increased for a number of the items. Motivation to do well (item 4) significantly declined across all samples/subsamples and agreement that learning accounting was a stressful experience strengthened (item 6). For item 5 'Accounting information is essential in business planning', only the qualitative TBL sample showed negative and significant results $(\mathrm{p}<.05)$. Although agreement that regular attendance in class was essential for good learning (item 7) declined across all four samples/subsamples, the decline for the control sample appeared larger. This was confirmed by an independent t-test (untabulated) between the TBL sample and control sample $(\mathrm{t}(32.76)=2.24, \mathrm{p}=0.03)$ and suggests that the TBL experience attenuated the decrease in agreement that regular class attendance is essential.

In conclusion, TBL appears to have some potential to mitigate the negative attitudes in introductory financial accounting courses but this effect is mostly seen in quantitatively inclined students.

\section{TBL perceptions}

Recall research question 2 asked whether TBL enhances student perceptions of the teamwork experience as a learning tool in accounting courses. One-way ANOVA was performed to determine whether there were any significant differences in the pre-test survey responses to the TBL learning experience variable based on each of the study's control variables. Undergraduates (UG) differed significantly from postgraduates (PG) in their pre-test responses, as did domestic (DOM) and international (INT) students. Therefore, analysis proceeded using the level and origin classifications. The data were split into four subsamples (UG DOM, UG INT, PG DOM and PG INT) for the paired sample t-tests to examine 
differences in the pre - post survey responses. Panel A in Table 4 presents the results of these four subsamples as well as the whole sample.

There were no significant differences between the pre- and post-test perceptions of TBL, hence providing a negative response to research question 2. The TBL experience was not found to enhance students’ perceptions of it as a learning tool in university accounting courses.

\section{[Insert Table 4 here]}

Table 4. Team-based learning perceptions and abilities - paired samples $t$ tests of TBL sample and subsamples comparing beginning of course with end

\begin{tabular}{|c|c|c|c|c|c|c|c|c|c|c|c|c|c|c|c|}
\hline \multirow[t]{2}{*}{$\begin{array}{l}\text { Panel A: Team-based learning } \\
\text { perceptions }\end{array}$} & \multicolumn{3}{|c|}{ TBL Sample } & \multicolumn{3}{|c|}{ UG DOM } & \multicolumn{3}{|c|}{ UG INT } & \multicolumn{3}{|c|}{ PG DOM } & \multicolumn{3}{|c|}{ PG INT } \\
\hline & $\begin{array}{l}\text { Change } \\
\text { in Mean }\end{array}$ & $n$ & Sig & $\begin{array}{l}\text { Change } \\
\text { in Mean }\end{array}$ & $n$ & Sig & $\begin{array}{c}\text { Change } \\
\text { in } \\
\text { Mean }\end{array}$ & $n$ & Sig & $\begin{array}{c}\text { Change } \\
\text { in } \\
\text { Mean }\end{array}$ & $n$ & Sig & $\begin{array}{l}\text { Change } \\
\text { in } \\
\text { Mean }\end{array}$ & $n$ & Sig \\
\hline TBL learning experience & 0.07 & 181 & 0.35 & -0.05 & 84 & 0.65 & 0.13 & 56 & 0.38 & 0.17 & 7 & 0.50 & 0.25 & 34 & 0.20 \\
\hline
\end{tabular}

\begin{tabular}{|l|c|c|c|c|c|c|c|c|c|}
\hline $\begin{array}{l}\text { Panel B: Team-based learning } \\
\text { abilities }\end{array}$ & \multicolumn{3}{|c|}{ TBL Sample } & \multicolumn{3}{c|}{ Work Experience } & \multicolumn{2}{c|}{ No Work Experience } \\
\hline & $\begin{array}{c}\text { Change } \\
\text { in Mean }\end{array}$ & $n$ & Sig & $\begin{array}{c}\text { Change } \\
\text { in Mean }\end{array}$ & $n$ & Sig & $\begin{array}{l}\text { Change } \\
\text { in Mean }\end{array}$ & $n$ & Sig \\
\hline Cultural diversity abilities & 0.22 & 181 & $\mathbf{0 . 0 0 ^ { * * * }}$ & 0.20 & 136 & $\mathbf{0 . 0 0 ^ { * * * * }}$ & 0.27 & 45 & $\mathbf{0 . 0 0 ^ { * * * }}$ \\
\hline Soft skills and leadership abilities & 0.17 & 181 & $\mathbf{0 . 0 0 ^ { * * * }}$ & 0.16 & 136 & $\mathbf{0 . 0 1 * *}$ & 0.20 & 45 & 0.11 \\
\hline Plamning and implementation abilities & 0.20 & 181 & $\mathbf{0 . 0 0 ^ { * * * }}$ & 0.20 & 136 & $\mathbf{0 . 0 0 ^ { * * * }}$ & 0.20 & 45 & $\mathbf{0 . 0 8}^{*}$ \\
\hline
\end{tabular}

Planning and implementation abilitie

Notes: Changes in mean calculated as post-test mean minus pre-test mean. Subsamples are from TBL sample and defined as follows: UG DOM = undergraduate domestic students; UG INT = undergraduate international students; PG DOM = postgraduate domestic students; PG INT = postgraduate international students.

\section{TBL abilities}

Recall research question 3 asked whether TBL in accounting courses enhances student perceptions of their abilities to work effectively in diverse teams. Perceptions of these abilities were captured in three variables: cultural diversity abilities; soft skills and leadership abilities; and planning and implementation abilities. One-way ANOVA was performed to determine whether there were any significant differences in the pre-test survey responses to these three variables based on each of the study's control variables. Only one significant difference was found. Students with work experience had a significantly $(\mathrm{p}<.01)$ higher pretest mean perception of their cultural diversity abilities compared to students with no work experience. Therefore, analysis proceeded using the whole TBL sample as well as the work experience classifications in paired sample t-tests for differences in the pre - post survey responses. The results are presented in panel B of Table 4.

All three measures provide evidence that students rated their abilities to work in teams as enhanced when comparing their scores at the beginning of the semester with those at the end. In the whole TBL sample, means for cultural diversity abilities, soft skills and leadership abilities and planning and implementation abilities all increased significantly $(\mathrm{p}<0.01)$ 
following the TBL experience. On average, students with work experience perceived an increase in their abilities on all three dimensions, while students without work experience perceived an increase only in their cultural diversity abilities and planning and implementation abilities. There was no significant difference between pre- and postresponses of students with no work experience on soft skills and leadership abilities ( $\mathrm{p}=$ 0.11). Although students with work experience started their TBL experience with higher perceived cultural diversity abilities compared to students without work experience, both samples of students appear to have benefited from the TBL experience. Hence there is a clear positive response to research question 3. The implementation of TBL in accounting courses does appear to enhance students' perceptions of their abilities to work effectively in diverse teams.

\section{Abilities and preferences in role performance}

Recall research question 4 asked whether TBL has a positive impact on students’ perceived abilities and preferences for roles that commonly emerge in teams. This study used the five roles that emerge in teams, task leader, socio-emotional leader, devil’s advocate, tension releaser, and information provider (Cragan et al., 2008). The survey instrument asked students to rate both their ability and preference in performing each of the five roles before and after the TBL experience. One-way ANOVA was performed to determine whether there were any significant differences in the pre-test survey responses measuring perceived ability and preference in performing in each of the five roles based on each of the study's control variables. No significant differences were found in students’ perceived ability in performing each of the five roles and so analysis proceeded using the whole TBL sample in paired sample t-tests for differences in the pre - post survey responses. The results of these analyses are presented in panel A of Table 5.

[Insert Table 5 here] 
Table 5. Group role abilities and preferences - paired samples $t$ tests of TBL sample and level comparing beginning of course with end

\begin{tabular}{|c|c|c|c|c|c|c|c|c|c|}
\hline \multirow[b]{2}{*}{ Panel A: Ability in performing the role } & \multicolumn{3}{|c|}{ TBL Sample } & \multicolumn{3}{|c|}{ TBL Undergraduates } & \multicolumn{3}{|c|}{ TBL Postgraduates } \\
\hline & $\begin{array}{l}\text { Change } \\
\text { in Mean }\end{array}$ & $n$ & Sig & $\begin{array}{l}\text { Change } \\
\text { in Mean }\end{array}$ & $n$ & Sig & $\begin{array}{l}\text { Change } \\
\text { in Mean }\end{array}$ & $n$ & Sig \\
\hline Task Leader & 0.17 & 173 & $0.02^{*+}$ & $\mathrm{n} / \mathrm{a}$ & $\mathrm{n} / \mathrm{a}$ & $\mathrm{n} / \mathrm{a}$ & $\mathrm{n} / \mathrm{a}$ & $\mathrm{n} / \mathrm{a}$ & $\mathrm{n} / \mathrm{a}$ \\
\hline Devil's Advocate & 0.03 & 173 & 0.76 & $\mathrm{n} / \mathrm{a}$ & $\mathrm{n} / \mathrm{a}$ & n/a & $\mathrm{n} / \mathrm{a}$ & $\mathrm{n} / \mathrm{a}$ & $\mathrm{n} / \mathrm{a}$ \\
\hline Tension Releaser & 0.08 & 173 & 0.33 & $\mathrm{n} / \mathrm{a}$ & $\mathrm{n} / \mathrm{a}$ & $\mathrm{n} / \mathrm{a}$ & $\mathrm{n} / \mathrm{a}$ & $\mathrm{n} / \mathrm{a}$ & $\mathrm{n} / \mathrm{a}$ \\
\hline Information Provider & 0.23 & 172 & $0.01^{*+}$ & $\mathrm{n} / \mathrm{a}$ & $\mathrm{n} / \mathrm{a}$ & $\mathrm{n} / \mathrm{a}$ & $\mathrm{n} / \mathrm{a}$ & $\mathrm{n} / \mathrm{a}$ & $\mathrm{n} / \mathrm{a}$ \\
\hline Socio-emotional leader & 0.17 & 171 & $0.06^{*}$ & 0.16 & 134 & 0.11 & 0.22 & 37 & 0.34 \\
\hline Devil's Advocate & 0.06 & 171 & 0.60 & 0.09 & 134 & 0.46 & -0.05 & 37 & 0.84 \\
\hline Tension Releaser & 0.06 & 172 & 0.52 & 0.07 & 134 & 0.57 & 0.05 & 38 & 0.77 \\
\hline Information Provider & 0.15 & 172 & 0.11 & 0.13 & 134 & 0.23 & 0.21 & 38 & 0.23 \\
\hline
\end{tabular}

There was a significant difference $(\mathrm{p}<0.05)$ in students' perceptions of their ability to perform the roles of task leader, socio-emotional leader, and information provider. Perceived ability in each of these three roles increased post-TBL. This suggests that TBL may have been a factor in developing students' leadership abilities in managing, supporting, and communicating within a team environment. No significant differences in the ability to perform the roles of devil's advocate and tension releaser were found.

Initial one-way ANOVA indicated significant differences in role preferences between UG and PG students. Therefore, the analysis of preference for each role proceeded using the whole TBL sample as well as the level classifications. The results of these analyses are presented in panel B of Table 5.

Across the whole TBL sample, there was a significant positive difference in students' preferences for the roles of task leader $(p<0.01)$ and socio-emotional leader $(p<0.10)$. This indicates that the experience of TBL empowered students to be more willing to lead projects and to nurture others in a diverse team. At the end of the courses, students’ preferences for performing the role of information provider were not significantly different, and a similar result was found for students' preferences for performing the roles of devil's advocate and tension releaser.

Similar to our results for the whole TBL sample, analysis based on level of studies (UG and PG) showed positive and significant results ( $\mathrm{p}<0.05$ and $\mathrm{p}<0.10$ respectively) for students' preferences to act as task leader. No significant differences were found in preference for the other four roles.

Overall, there is some evidence to suggest that TBL has a positive impact on student's perceived abilities and preferences in performing some team roles. Therefore, at the level of 
degree studied, the response to research question 4 is not an unambiguous 'yes' or 'no', but rather the positive response is limited to the preference for the leadership roles.

\section{Discussion}

Hellier (2013) promotes the importance of an effective education approach to teaching and learning accounting. We heeded Warren and Young's (2012) encouragement to rethink strategies for enhancing student learning in introductory accounting courses in an effort to reduce negative perceptions of accounting, and introduced TBL, a non-traditional pedagogy. Details of our motivations and our results have been presented in previous sections. This section provides a brief summary of our results and discussion in the context of the literature.

Research question 1 was concerned with students' perceptions and attitudes towards accounting and whether TBL was an enhancing factor for those perceptions and attitudes. While occasioning mixed results, our study yielded mostly discouraging findings. Taken together, our results indicate that students’ perceptions and attitudes towards learning accounting mostly declined. However, our findings are not dissimilar to those of Marriott and Marriott (2003) whose focus was on a meta-analysis of students' attitudes towards accounting as a profession. These researchers determined that students liked accounting less at the end of their course than they did at the start. Our study suggests that in some respects, TBL helped reduce these negative perceptions and attitudes.

Research question 2 sought to determine students' perceptions on whether TBL enhanced students' teamwork experience as a learning tool in accounting subjects. Again, overall, our results disappointedly indicated that TBL did not produce an improvement in students' attitudes in this regard. As research into TBL shows that this instructional strategy is a superior learning tool (see, for example, Han \& Newell, 2014; Michaelsen, Watson, Cragin, \& Fink, 1982), we suggest that our findings indicate the following: student-resistance to a non-traditional learning approach (Michaelsen et al., 1982), and/or results are driven by students' negative attitudes towards the subject, rather than the pedagogical approach adopted. It is also possible that the student expectations expressed in the pre-test responses were met and therefore no change in post-test responses is not necessarily to be viewed negatively. Future research could consider alternative says to explore whether TBL is a superior learning tool in the accounting context. 
Research question 3 asked whether TBL in accounting courses enhances student perceptions of their abilities to work effectively in diverse teams. The literature provides evidence that a TBL environment for international students with English as a second language or a non-English speaking-background improves their English comprehension, speaking, and writing skills (Woodley \& Armatas, 2010). Although culturally pluralist teams may struggle to begin with, they show increased productivity (Cragan et al., 2008). This research supports the literature by providing evidence that TBL in accounting courses enhances student perceptions of their abilities to work effectively in diverse teams as well as enhancing other teamwork abilities.

Research question 4 is concerned with student perceptions of abilities and preferences for the different roles that emerge in a TBL environment. The most significant results were for the leadership roles of task leader and socio-emotional leader, where the TBL experience positively enhanced students' perceptions of both their both the ability and preference in performing the roles. Given these roles were described as leading with the aim of problem solving (task leader) and providing nurturing and emotional support (socio-emotional), our results suggest that by providing a TBL environment, universities are fulfilling their commitment towards delivering those graduate attributes concerned with leadership and teamwork. It also suggests that TBL increases students' confidence in taking on key leadership roles and therefore enhances their employability. This is further supported by enhanced student perceptions of their ability to perform in the role of information provider where a key characteristic of this role was to provide accurate and reliable data, a critical attribute for those in the accounting profession.

\section{Conclusion}

TBL requires instructors to adopt a new pedagogical approach and create an environment that places more emphasis on teaching the skills and strategies to better engage and equip students for professional life. Whilst the core knowledge areas of introductory accounting programs are determined by the profession, and thus the learning outcomes must be aligned with these, significant modifications can be made to the delivery and assessment of accounting courses. Traditional teaching methods at universities are increasingly being viewed as out-dated and inappropriate for the learning styles of new generations of students. Most of the student population are digital learners with distinct characteristics and learning expectations different from many of their instructors (Skiba \& Barton, 2006). With students’ preferences for digital 
delivery, experiential learning, interactivity, and immediacy, the challenge for faculty is adapting current teaching strategies to accommodate the learning needs of these digital learners (Skiba \& Barton, 2006). In response, flipping the classroom is becoming an increasingly popular paradigm in tertiary education and TBL is key feature of this approach.

Accounting educators also face the challenge of teaching content that is highly technical to a broad range of students, some of whom find the technical content particularly difficult. Part of the challenge is to change students' negative perceptions of accounting through engaging content and motivating context. This research set out to do this by implementing TBL in accounting courses. Compared to a control sample, our findings suggest that the TBL experience improved some attitudes towards accounting, particularly among quantitatively inclined students. After experiencing TBL, students believed their teamwork abilities had improved, particularly those related to cultural diversity. Students generally believed that their ability in performing the roles of task leader, socio-emotional leader, and information provider improved significantly, as did their preferences for performing the two leadership roles.

We acknowledge that there are a number of limitations to this study. The sample is confined to one university within a discrete time period of 1 year and limited to one discipline area, accounting. There is scope to expand knowledge of the development of roles in a TBL environment through measuring students' perceptions and abilities at different points, by taking one cohort and collecting data throughout their degree.

A last word on our TBL experience. The original instructors continue to be keen advocates of TBL, and as their teaching roles have changed, have implemented it in other accounting subjects, albeit sometimes with slight modifications depending on the subject. Given that most universities and professional bodies (AICPA, 2011) include communication and leadership, plus global citizenship, as graduate attributes for, and core competencies of business graduates, we encourage others to embed TBL into accounting and other curricula, thereby satisfying the needs of all stakeholders: students, faculty, and employers.

\section{Acknowledgements}

The authors would like to thank Marilyn Mitchell for her inspirational seminar and ongoing support and guidance in the implementation of team-based learning; Ben Shaw and Ken Parry for their generosity, expertise and time in the development of the survey instrument. 
Ken sadly passed away in February 2018. Our sincere thanks are extended to the three anonymous reviewers for their generous and insightful contributions to this paper.

\section{References}

Adler, R. W., \& Milne, M. J. (1997). Improving the quality of accounting students' learning through action-oriented learning tasks. Accounting Education, 6(3), 191-215. doi:10.1080/096392897331442

American Institute of Certified Professional Accountants (AICPA)(2011). CPA Horizons 2025 Report. [Author]. Retrieved from http://www.aicpa.org/research/cpahorizons2025/downloadabledocuments/cpahorizons-report-web.pdf

Anson, R., \& Goodman, J. A. (2014). A Peer Assessment System to Improve Student Team Experiences. Journal of Education for Business, 89(1), 27-34. doi:10.1080/08832323.2012.754735

Betta, M. (2016). Self and others in team-based learning: Acquiring teamwork skills for business. Journal of Education for Business, 91(2), 69-74. doi:10.1080/08832323.2015.1122562

Biggs, J. (1987). Student approaches to learning and studying. Camberwell: Australian Council for Educational Research.

Bowen, S. (2005). Engaged learning: Are we all on the same page? Peer Review: Science and Engaged Learning, 7(2). Retrieved from https://www.aacu.org/publicationsresearch/periodicals/engaged-learning-are-we-all-same-page

Bryant, S. M., \& Albring, S. M. (2006). Effective team building: Guidance for accounting educators. Issues in Accounting Education, 21(3), 241-265.

Butt, A. (2014). Student views on the use of a flipped classroom approach: Evidence form Australia. Business Education \& Accreditation, 6(1), 33-43. 
Caldwell, M. B., Weishar, J., William, \& Glezen, G. (1996). The effect of cooperative learning on student perceptions of accounting in the principles courses. Journal of Accounting Education, 14(1), 17-36. doi:10.1016/0748-5751(95)00032-1

Candy, P. C. (2000). Reaffirming a proud tradition: Universities and lifelong learning. Active Learning in Higher Education, 1(2), 101-125.

Chen, C.-H., \& Law, V. (2016). Scaffolding individual and collaborative game-based learning in learning performance and intrinsic motivation. Computers in Human Behavior, 55(2016), 1201-1212. doi:10.1016/j.chb.2015.03.010

Clinton, B. D., \& Kohlmeyer III, J. M. (2005). The effects of group quizzes on performance and motivation to learn: Two experiments in cooperative learning. Journal of Accounting Education, 23(2), 96-116. doi:10.1016/j.jaccedu.2005.06.001

Cochran, J. D., Campbell, S. M., Baker, H. M., \& Leeds, E. M. (2014). The role of student characteristics in predicting retention in online courses. Research in Higher Education, 55(1), 27-48

Cohen, J., \& Hanno, D. M. (1993). An analysis of underlying constructs affecting the choice of accounting as a major. Issues in Accounting Education, 8(2), 219-238.

Cooper, J., \& Mueck, R. (1990). Student involvement in learning: Cooperative learning and college instruction. Journal on Excellence in College Teaching, 1, 68-76.

Cragan, J. F., Wright, D. W., \& Kasch, C. R. (2008). Communication in small groups: Theory, process and skills (with InfoTrac) (Wadsworth series in speech communication). Portland, OR: Green Earth Books.

Crebert, G., Bates, M., Bell, B., Patrick, C., \& Cragnolini, V. (2004). Developing generic skills at university, during work placement and in employment: graduates’ perceptions. Higher Education Research \& Development, 23(2), 147-165.

Dochy, F., Segers, M., \& Sluijsmans, D. (1999). The use of self-, peer and co-assessment in higher education: A review, 24(3), 331-350. 
Fosnot, C. T., \& Perry, R. S. (1996). Constructivism: A psychological theory of learning. Constructivism: Theory, perspectives, and practice, 2, 8-33.

Gomez, E. A., Wu, D., \& Passerini, K. (2010). Computer-supported team-based learning: The impact of motivation, enjoyment and team contributions on learning outcomes. Computers \& Education, 55(1), 378-390. doi:https://doi.org/10.1016/j.compedu.2010.02.003

Han, G., \& Newell, J. (2014). Enhancing Student Learning in Knowledge-Based Courses: Integrating Team-Based Learning in Mass Communication Theory Classes. Journalism \& Mass Communication Educator, 69(2), 180-196. doi:10.1177/1077695813517887

Handal, B., Wood, L., \& M. Muchatuta. (2011). Students’ expectations of teaching: The business, accounting and economics experience. e-Journal of Business Education \& Scholarship of Teaching, 5(1), 1- 17

Helliar, C. (2013). The Global Challenge for Accounting Education. Accounting Education, 22(6), 510-521. doi:10.1080/09639284.2013.847319

IFAC International Accounting Education Standards Board. (2017). Handbook of International Education Pronouncements. [Author]. Retrieved from https://www.ifac.org/system/files/publications/files/2017-Handbook-of-InternationalEducation-Pronouncements.PDF

Johnson, D. W., \& Johnson, R. T. (1999). Making cooperative learning work. Theory into Practice, 38(2), 67-73. doi:10.2307/1477225

Kahu, E., Stephens, C., Leach, L., \& Zepke, N. (2015). Linking academic emotions and student engagement: Mature-aged distance students’ transition to university. Journal of Further and Higher Education, 39(4), 481-497.

Kapp, K. M., \& O'Driscoll, T. (2009). Learning in 3D : Adding a new dimension to enterprise learning and collaboration (1st ed.). Retrieved from http://scu.eblib.com.au/patron/FullRecord.aspx?p=479867 
Kavanagh, M. H., \& Drennan, L. (2008). What skills and attributes does an accounting graduate need? Evidence from student perceptions and employer expectations. Accounting \& Finance, 48(2), 279-300.

Lage, M. J., Platt, G. J., \& M. Treglia (2000) Inverting the classroom: A gateway to creating an inclusive learning environment. Journal of Economic Education, 31(1), 30-43.

Lightner, S., Bober, M. J., \& Willi, C. (2007). Team-based activities to promote engaged learning. College Teaching, 55(1), 5-18. doi:10.3200/ctch.55.1.5-18

Marriott, P., \& Marriott, N. (2003). Are we turning them on? A longitudinal study of undergraduate accounting students' attitudes towards accounting as a profession. Accounting Education, 12(2), 113-133. doi:10.1080/0963928032000091738

Michaelsen, L. K., Bauman Knight, A., \& Fink, L. D. (2002). Team-based Learning: a transformative use of small groups in college teaching. Sterling, VA: Stylus.

Michaelsen, L. K., \& Sweet, M. (2008). The essential elements of team-based learning. New Directions for Teaching and Learning, 2008(116), 7-27. doi:10.1002/tl.330

Michaelsen, L. K., \& Sweet, M. (2011). Team-based learning. New Directions for Teaching \& Learning, 2011(128), 41-51. doi:10.1002/tl.467

Michaelsen, L. K., Watson, W., Cragin, J. P., \& Fink, D. A. (1982). Team Learning: a Potential Solution To the Problems of Large Classes. Exchange: The Organizational Behavior Teaching Journal, 7(1), 13-22. doi:10.1177/1052562982007001033

Myers, S. A., \& Anderson, C. M. (2008). The fundamentals of small group communication: Sage.

Nelson, I. T. (1995). What's new about accounting education change? An historical perspective on the change movement. Accounting Horizons, 9(4), 62-75.

Opdecam, E., \& Everaert, P. (2012). Improving student satisfaction in a first-year undergraduate accounting course by team learning. Issues in Accounting Education, 27(1), 53-82. doi:10.2308/iace-10217 
Paguio, R., \& B. Jackling (2016).Teamwork from accounting graduates: What do employers really expect? Accounting Research Journal, 29(3), 348-344. doi: 10.1108/ARJ-052014-0049.

Reinig, B.A., Horowitz, I. \& Whittenburg, G.E. (2011). The effect of team-based learning on student attitudes and satisfaction. Decision Sciences Journal of Innovative Education, 9(1), 27-47.

Rothwell, J. D. (2013). In mixed company: Communicating in small groups (8 ed.): Cengage Learning.

Shaw, J. B., Fisher, C. D., \& Southey, G. N. (1999). Evaluating organizational behaviour teaching innovations: More rigorous designs, more relevant criteria, and an example. Journal of Management Education, 23(5), 509-536.

Shaw, J. B. (2004). A fair go for all? The impact of intragroup diversity and diversitymanagement skills on student experiences and outcomes in team-based class projects. Journal of Management Education, 28(2), 139-169.

Skiba, D., \& Barton, A. (2006). Adapting your teaching to accommodate the net generation of learners. The Online Journal of Isssues in Nursing, 11(2), 1-11.

Swanson, E., McCulley, L. V., Osman, D. J., Scammacca Lewis, N., \& Solis, M. (2017). The effect of team-based learning on content knowledge: A meta-analysis. Active Learning in Higher Education, 1469787417731201. doi:10.1177/1469787417731201

van der Laan Smith, J., \& Spindle, R. M. (2007). The impact of group formation in a cooperative learning environment. Journal of Accounting Education, 25(4), 153-167. doi:10.1016/j.jaccedu.2007.09.002

Vygotsky, L. (1978). Mind in society. London: Harvard University Press.

Warren, D. L., \& Young, M. N. (2012). Integrated accounting principles: A best practices course for introductory accounting. Issues in Accounting Education, 27(1), 247-266. doi:10.2308/iace-50106 
Wood, D., \& Bruner, J. S., \& Ross, G. (1976). The role of tutoring in problem solving. Journal of Child Psychology and Psychiatry, 17(1), 89-100.

Woodley, C., \& Armatas, C. (2010). Teamwork: The process and the product: What students think. International Journal of Learning, 17(4), 527-537. 
Appendix Survey instrument items

\section{Demographics}

- Gender

- What is your age?

- What country are you from?

- What is the name of the degree you are studying?

- Do you have any work experience and if so how many years and months \& main activity?

\section{Course Specific Attitudes:}

1. My level of knowledge about accounting is: none, very little, some, moderate, high, very high

Following Likert scale - strongly disagree, disagree, slightly disagree, agree, strongly agree

2. Accounting is interesting

3. You must understand accounting to solve business problems

4. I am motivated to do well in this course

5. Accounting information is essential in business planning

6. Learning accounting is a stressful experience

7. Regular attendance in this class is essential for good learning

8. I plan to take on a career in accounting once I have graduated from university

Perceptions \& Abilities - please indicate the level of perception and ability you currently have in the following areas: almost none, very low, low, moderate, high, very high

\section{Team-Based Learning Perceptions:}

1. Team-based learning is an enjoyable experience

2. Team-based learning is an effective learning tool

3. Team-based learning enhances my problem solving and decision making skills

4. Team-based learning impacts positively on my grade

5. Team-based learning is a satisfying experience

\section{My Ability to:}

1. Communicate effectively with people from cultures other than my own

2. Communicate my point of view effectively in a team-based learning environment

3. Develop "win-win" situations when there is conflict in a team-based learning environment

4. Manage interpersonal conflict effectively in a team-based learning environment

5. Negotiate with team members who are from a different culture than myself

6. Understand a situation from a perspective other than my own

7. Work effectively with others in a team-based learning environment

8. Develop effective work plans in a multicultural or diverse team

9. Manage workload within a team-based learning environment

10. Be accountable within a team-based learning environment

11. Work effectively with people from cultural backgrounds different from my own

12. Motivate others in a team-based learning environment 


\section{Group Membership Qualities}

In all groups, individual members tend to take on various roles. Sometimes they may perform primarily one role and in other situations they may perform a variety of roles over the life of the group. Five such roles are listed below. How do you currently rate your ability and preference in performing the following roles? (almost none, very low, low, moderate, high, very high)

1. Task Leader - coordinates activities, ensures all group members participate, have the opportunity to learn $\&$ are respected as persons. Keeps team on track to complete the assigned task.

2. Socio-emotional Leader - plays a nurturing role, provides emotional support to team members and task leader.

3. Devil's Advocate - challenges a position or perspective when there is debate by arguing for something you may not necessarily agree with.

4. Tension Releaser - keeps the team relaxed through humour so the group is emotionally able to do its work.

5. Information Provider - acts as a researcher and helper to others in the group. 